Morris, J. N., Heady, J. A., Raffle, P. A. B., Roberts, C. G. \& Parks, J. W. (1953a). Lancet, 265, 1053. Morris, J. N., Heady, J. A., Raffle, P. A. B., Roberts, C. G. \& Parks, J. W. (r953b). Lancet, 265, i I I I. Ministry of Agriculture, Fisheries and Food: National Food Survey Committee. (1960). Domestic Food Consumption and Expenditure, 1958, p. 64. London: H.M. Stationery Office.

\title{
Food habits in pregnancy
}

\section{By Nan Taggart, Obstetric Medicine Research Unit (Medical Research Council), Maternity Hospital, Aberdeen}

Many factors, geographical, social, economic and cultural, combine to determine human dietary habits, which vary widely between individuals and between groups. Any changes, quantitative or qualitative, which may take place as a result of pregnancy will be superimposed on pre-existing food habits. The changes may occur spontaneously, or they may occur in consequence of education or other outside influence.

\section{Background variations in food habits}

Differences in food habits between economic groups in this country were first highlighted in Food, Health and Income (Orr, 1937), and are now summarized annually in reports from the Ministry of Agriculture, Fisheries and Food. A marketing research organization has recently described some of the regional as well

Table I. Percentage distributions of meal patterns in three social classes of Aberdeen primigravidae, 1950-53

\begin{tabular}{|c|c|c|c|}
\hline \multirow{3}{*}{ Type of meal } & \multicolumn{3}{|c|}{ Social class* } \\
\hline & I and II $(76)$ & III $(187)$ & IV and $V(46 I)$ \\
\hline & \multicolumn{3}{|c|}{ Breakfasts on weekdays } \\
\hline None & 0.2 & $2 \cdot 5$ & $2 \cdot 5$ \\
\hline Tea and roll & $2 x \cdot 7$ & $44 \cdot 5$ & $58 \cdot 1$ \\
\hline Porridge or cereal & 50.0 & $4 I \cdot 2$ & $30 \cdot 2$ \\
\hline Cooked dish without cereal & $15 \cdot 8$ & 10.0 & $8 \cdot 5$ \\
\hline Two-course & $12 \cdot 3$ & I. 8 & 0.7 \\
\hline \multicolumn{4}{|c|}{ Breakfasts on Sundays } \\
\hline None & 0 & $2 \cdot 7$ & $1 \cdot 3$ \\
\hline Tea and roll & 14.5 & $16 \cdot 0$ & $16 \cdot 5$ \\
\hline Porridge and cereal & $22 \cdot 4$ & I $1 \cdot 8$ & $8 \cdot 9$ \\
\hline Cooked dish without cereal & $44 \cdot 7$ & $65 \cdot 8$ & $70 \cdot 7$ \\
\hline Two-course & 184 & $3 \cdot 7$ & $2 \cdot 6$ \\
\hline \multicolumn{4}{|c|}{ Midday meals for whole week } \\
\hline None & $x \cdot 3$ & 0.6 & $0 \cdot 7$ \\
\hline One-course & $7 \cdot 0$ & rg.0 & $3 I \cdot 6$ \\
\hline Two-course & $60 \cdot 0$ & $60 \cdot 8$ & $53 \cdot 0$ \\
\hline Three-course & $3 x \cdot 7$ & $19^{\cdot 6}$ & 14.7 \\
\hline \multicolumn{4}{|c|}{ Evening meals for whole week } \\
\hline None & $\mathrm{I} \cdot 9$ & 0.7 & $x \cdot 4$ \\
\hline Plain tea & 13.7 & $8 \cdot 4$ & $5 \cdot 5$ \\
\hline High tea & $77 \cdot 3$ & $88 \cdot 6$ & 90.9 \\
\hline Dinner & $7 \cdot 1$ & $2 \cdot 3$ & $2 \cdot 2$ \\
\hline
\end{tabular}

* Figures in parentheses are the numbers of women. 
as social-class differences in the general pattern of food consumption and meal habits (Warren, 1958). The kind of differences existing between the social classes may be illustrated from the records of a dietary survey of primigravidae made in Aberdeen during $195^{\circ}-3$ (Thomson, 1958).

The usual sequence of meals was breakfast, dinner at midday, and high tea at night; breakfasts on Sundays were more elaborate than those on weekdays. Wives of men in professional and managerial occupations (social classes I and II) more often had a breakfast which included cereal or porridge or a cooked dish, more often had a three-course lunch, and less often had a one-course lunch than did the wives of skilled and unskilled manual workers (social classes III, IV and V) (see Table I). Women in social classes I and II more often had 'snacks' which included milk or a milk drink whereas those in the manual working classes more often drank tea with snacks between meals. Vegetables were eaten more regularly by women in the upper social classes; some women in social classes IV and V never had vegetables other than potatoes at dinner.

The same kinds of variations in the use of specific foods were found among pregnant women surveyed in other parts of Britain more than 20 years ago (McCance, Widdowson \& Verdon-Roe, 1938). Women in the poorest classes ate much less fruit, green vegetables, raw or salad vegetables, and milk, less meat, fish, brown bread and root vegetables including potatoes, but more legumes and much more white bread than women in the professional classes (Table 2).

Table 2. Mean daily intakes of some foods by groups of pregnant women in Britain, before and after the Second World War

\begin{tabular}{|c|c|c|c|c|c|c|c|c|c|}
\hline \multirow{3}{*}{$\begin{array}{l}\text { Source } \\
\text { McCance, } \\
\text { Widdowson \& } \\
\text { Verdon-Roe } \\
\text { (I938) }\end{array}$} & \multirow[b]{2}{*}{ Subjects* } & \multicolumn{8}{|c|}{$\begin{array}{l}\text { Mean daily intake } \\
\text { Raw }\end{array}$} \\
\hline & & $\begin{array}{l}\text { Milk } \\
\text { (oz) }\end{array}$ & $\begin{array}{l}\text { Eggs } \\
\text { (no.) }\end{array}$ & $\begin{array}{l}\text { Meat } \\
\text { (oz) }\end{array}$ & $\begin{array}{l}\text { Fish } \\
\text { (oz) }\end{array}$ & $\begin{array}{r}\text { fruit } \\
(o z)\end{array}$ & $\begin{array}{l}\text { Vegetables } \\
\text { (oz) }\end{array}$ & $\begin{array}{l}\text { Potatoes } \\
\quad(o z)\end{array}$ & $\begin{array}{c}\text { Bread } \\
\text { (oz) }\end{array}$ \\
\hline & $\begin{array}{l}\text { Poorest group, } \\
\text { husbands mostly } \\
\text { unemployed } \\
\text { (I6) }\end{array}$ & $8 \cdot 2$ & 0.4 & $I \cdot 7$ & 0.5 & 0.7 & $I \cdot 2$ & $2 \cdot 9$ & 10.5 \\
\hline & $\begin{array}{l}\text { Wealthiest group, } \\
\text { husbands } \\
\text { professional men } \\
\qquad(26)\end{array}$ & I $6 \cdot 4$ & 0.6 & $3 \cdot 1$ & $I^{\prime} 5$ & 5.7 & $4 \cdot 5$ & $3 \cdot 8$ & $4 \cdot 4$ \\
\hline Hobson (1948) & $\begin{array}{l}\text { Poor and middle- } \\
\text { class women } \\
\text { (I I I) }\end{array}$ & $17 \cdot 6$ & - & $3 \cdot 0$ & $r \cdot 5$ & - & 375 & $6 \cdot 5$ & 8.0 \\
\hline
\end{tabular}

Spontaneous changes in food habits during pregnancy

Appetite. Preliminary results of an inquiry we are making into changes in appetite and food habits during pregnancy show that rather more than half of the women who were questioned reported a definite increase in appetite. In about three-quarters of these the surge of appetite began during the first trimester. Increased thirst was 
even more common. The increases might persist throughout pregnancy, but just as often there was some lessening in the later months. An increase in appetite or thirst during the later months of pregnancy was much less common. In early pregnancy the energy requirement of the foetus is small and the basal metabolism of the mother is not greatly increased. An increase in appetite at this time, if it were accompanied by increased food intake, would suggest that maternal storage was taking place. On the other hand, almost half of the women failed to notice any increase in appetite during pregnancy. The question of whether or not their food intake was changed remains unanswered.

Snacks between meals assume greater importance for many women during pregnancy, in the early months because of increased appetite between meals and in the later months because of decreased capacity at main meals.

Nausea, vomiting and heartburn. In the same inquiry nausea and vomiting of early pregnancy, which affected about half of the women in varying degree, were sometimes accompanied by poor appetite and reduced food intake; fried or fatty foods, in particular, were avoided. However, it was much more usual for appetite to be normal or even increased in spite of nausea and vomiting. Heartburn, which was reported by about half of the women in the later months of pregnancy, rarely affected appetite although it might lead to a change in the choice of foods. The usual habit was to eat to appetite and to take an antacid to relieve heartburn.

Cravings and aversions. About two-thirds of these women developed some craving during pregnancy. All the cravings were for foods readily available, the most common being for fruit. Hobson (I948) has also noted an increased desire for fruit. Several women said they craved fruit partly because its juiciness helped to satisfy their thirst. Fairly frequent were cravings for strongly flavoured or savoury foods such as pickles, black puddings (blood sausages), liquorice, potato crisps, cheese and kippers. Sweets and chocolates were mentioned occasionally. Several women spontaneously developed a liking or even a craving for milk, although they did not enjoy it before pregnancy.

Aversions to certain foods occurred as often as cravings. In early pregnancy tea and coffee were often found to have a peculiar taste (sometimes described as a 'dry' taste), or to be insipid; this may be related to a change in the sense of smell, which is said to occur in some women during pregnancy. A dislike for tea was sometimes accompanied by an increased intake of milk. An aversion to fried food or the smell of food frying, and to eggs or the sight of eggs was quite common even among women who had no nausea. A few women, particularly in the later months of pregnancy, took a dislike to sweet foods and said that they came to prefer plain or savoury foods.

The majority of these primigravidae experienced some change in appetite or food preference during pregnancy, but the range of individual variation was wide. The significance of the changes is unknown. Some may be related to altered requirements. The changes bore no apparent relation to the patient's knowledge of, or opinions about, nutrition. 
Harries \& Hughes (I957) described the response to a broadcast in which listeners were invited to write to the B.B.C. about their food cravings during pregnancy. Of the $99 \mathrm{I}$ cravings reported in 509 letters most were for fruit, usually the readily available kinds, and for vegetables, especially raw vegetables. Confectionery, pickles and cereal products were mentioned often, and spices and condiments occasionally. Aversions were mentioned much less frequently than cravings; the commonest were for tea, coffee and smoking.

Pica, the craving for substances usually considered inedible, has been known since ancient times, and appears to occur more frequently among children and pregnant women than among other sections of the population (Cooper, 1957). There is some evidence that pica may be associated with iron-deficiency anaemia or with sideropenia and that it disappears when medicinal iron is given (Lanzkowsky, 1959; Carlander, 1959). In response to the B.B.C. broadcast mentioned earlier 187 instances of pica were reported. The inedible substances craved by these women in Britain included coal, soap, disinfectant, toothpaste, plaster, whitewash and chalk. Harries $\&$ Hughes point out that the reports may be biassed towards the unusual, and by what was said in the broadcast. Pica certainly is uncommon in Aberdeen. Of 800 women attending an antenatal clinic who discussed their diets with a dietitian, none mentioned pica, and of another 100 who were specifically asked, only one had experienced pica. This woman had an irresistable urge to eat coal and spent match-heads during the last 6 weeks of her pregnancy. She was mildly amused by the phenomenon, and discussed it freely. She had a marked preference for good-quality coal which crunched in a satisfying manner, and she consumed about 2 dozen sweet-sized pieces daily. The craving disappeared immediately after delivery.

\section{Changes promoted by dietary education}

It is generally agreed that nutritional requirements are increased during pregnancy. Dietary education at antenatal clinics, through articles in women's magazines, and as a result of government policy during and since the Second World War has made women in Britain more conscious of their dietary habits and has been instrumental in improving these habits. Possibly, however, the disappearance of extreme poverty and the rise in 'working-class' standards of living have been the most important factors in raising nutritional standards. Table 2 shows that the mean intakes of important foods by II 1 poor and middle-class women in Bristol in 1947 (Hobson, 1948) were very similar to the intakes by the wealthiest group studied by McCance, Widdowson \& Verdon-Roe (1938).

Dietary education is not equally effective in all sections of the community. There are social-class differences in the consumption of orange juice and vitamin $\mathrm{A}$ and $\mathrm{D}$ concentrates as well as in the consumption of milk during pregnancy (Marr, Hope, Stevenson \& Thomson, I955). Levels of intake by Aberdeen primigravidae studied between $195^{\circ}$ and 1953 are shown in Table 3 . The increase during pregnancy in the intake of milk by these women is not known. A social-class gradient in milk intake probably existed before pregnancy, but a greater increase in milk consumption during pregnancy by the women in the higher social groups would also be 
expected. Specific inquiries at an antenatal clinic in Aberdeen show that many women know, before their first clinic visit, that milk and fresh fruit are 'good for them' although other knowledge of nutrition is usually slight. Some women deliberately increased their milk intake when they knew they were pregnant, even before they had obtained tokens for extra milk at a reduced price. Usually, however, milk intake was unchanged at the time of the first clinic visit. The majority of women who were advised to increase a low milk intake did so.

Table 3*. Percentages of Aberdeen primigravidae, 1950-3, having various intakes of milk and vitamin concentrates by social class

\begin{tabular}{|c|c|c|c|}
\hline Husband's social class & I and II & III & IV and $\mathrm{V}$ \\
\hline \multicolumn{4}{|l|}{ Mean daily intake of milk (all sources): } \\
\hline$x$ pint or more & $5^{8}$ & 43 & 18 \\
\hline$\frac{1}{2}-1$ pint & 36 & 45 & 59 \\
\hline Less than $\frac{1}{2}$ pint & 6 & 12 & 23 \\
\hline No. of women & 69 & 153 & 323 \\
\hline \multicolumn{4}{|l|}{$\begin{array}{l}\text { Consumption of vitamins } \mathrm{A} \text { and } \mathrm{D} \\
\text { concentrates: }\end{array}$} \\
\hline Regular ( 5 days or more in week) & 60 & 52 & $4 \mathrm{I}$ \\
\hline Irregular & I2 & 12 & Io \\
\hline None & 28 & 35 & 49 \\
\hline \multicolumn{4}{|l|}{ Consumption of orange juice concentrate: } \\
\hline Regular ( 5 days or more in week) & 53 & 42 & $3 \mathrm{I}$ \\
\hline Irregular & 12 & 18 & 20 \\
\hline None & 36 & 40 & 49 \\
\hline No. of women & 76 & 187 & $46 \mathrm{I}$ \\
\hline
\end{tabular}

\section{Comment}

Knowledge of the optimum nutritional requirements of the mother and foetus during pregnancy is still far from complete. At present food habits which result in intakes of nutrients similar to those recommended by the British Medical Association: Committee on Nutrition (I950) or by the (U.S.A.) National Research Council: Food and Nutrition Board (1958) are believed to be good food habits.

In this country during the last war the vigorous government policy of nutrition education and food priorities for pregnant women must have had an impact on food habits which were already forcibly altered because many customary items of diet were not available. Probably as a result, there was a dramatic fall in the stillbirth and neonatal death rates during the same period (Duncan, Baird \& Thomson, 1952). With the return of a free economy the choice of food is again largely a matter of personal preference. This may or may not have anything to do with the fact that stillbirth and neonatal death rates have shown little improvement during the past decade. Though frank malnutrition is rare there is no reason to think that the present food habits of expectant mothers in Britain result in optimal nutrition.

At the same time, it is important to keep in mind the limitations as well as the possibilities of dietary education at antenatal clinics. Thomson (I959) has pointed out that, in reasonably well-fed communities, the clinical importance of diet in pregnancy is 
difficult to demonstrate. That is to say, the work of the dietitian may have little or no obvious influence upon the incidence of abnormalities such as stillbirth, premature birth, and even pre-eclampsia. Nevertheless, dietary education has a useful place in the management of nausea and vomiting, heartburn, constipation, obesity and oedema; and its most important benefits may be felt in the future, if, as a result of dietary teaching, the mother of today feeds her children better and thus helps to produce a better-grown, healthier, and better-informed next generation.

The values in Table I have been taken from an unpublished analysis of the Aberdeen data by Miss E. B. Hope, Miss J. W. Marr and Miss J. D. Stevenson, to whom I wish to express my thanks.

\section{REFERENCES}

British Medical Association: Committee on Nutrition (1950). Report of the Committee on Nutrition. London: British Medical Association.

Carlander, O. (1959). Lancet, ii, 569.

Cooper, M. (1957). In Pica. Springfield, Ill.: Charles C. Thomas.

Duncan, E. H. L., Baird, D. \& Thomson, A. M. (1952). F. Obst. Gynaec., Brit. Emp., 59, 183.

Harries, J. M. \& Hughes, T. F. (1957). Proc. Nutr. Soc. 16, xx.

Hobson, W. (1948). 7. Hyg., Camb., 46, 198.

Lanzkowsky, P. (1959). Arch. Dis. Childh. 34, I40.

Marr, J. W., Hope, E. B., Stevenson, J. D. \& Thomson, A. M. (1955). Proc. Nutr. Soc. 14, vii.

McCance, R. A., Widdowson, E. M. \& Verdon-Roe, C. M. (ı938). F. Hyg., Camb., 38, 596.

National Research Council: Food and Nutrition Board (1958). Publ. nat. Res. Coun., Wash., no. 589.

Ort, J. B. (1937). Food, Health and Income. London: Macmillan \& Co.

Thomson, A. M. (1958). Brit. F. Nutr. 12, 446.

Thomson, A. M. (1959). Brit. F. Nutr. r3, 509.

Warren, G. C. (editor) (I958). The Foods We Eat. London: Cassell \& Co. Ltd.

\section{Flavour and flavour acceptance}

By Mary Andross, Glasgow and West of Scotland College of Domestic Science, I Park Drive, Glasgow, C.3

In this paper the subject is treated in three sections, namely the physiology and the chemistry of flavour, and the methods used by tasting panels.

\section{Physiology}

Flavour involves principally the three senses-touch, taste and smell. Appearance of food is also important, as was found in our experiments with battery and 'free-run' eggs. The free-run eggs have usually a deeper colour and a slightly stronger texture, due to a stronger, thicker white. When organoleptic tests were performed with a panel blind-folded, flavour comparisons showed little difference between the eggs. However, highly significant results were obtained in favour of the free-run eggs when the panel were allowed to see the product, as scrambled eggs or as custards, sponges and cakes.

Sound may also be part of flavour acceptance. The sound of a breaking biscuit or shortbread, the crunch of toffee and of a hard apple have all a definite appeal. 